\title{
Local excision vs. radical surgery in treating rectal nets considering the biology of neuroendocrine tumors (NETs)
}

\author{
Mykola Zubaryev' ${ }^{1}$ Kim Ho Seung ${ }^{2}$, Min Byung Soh² \\ 'Department of the Abdominal Tumors, National Cancer Institute, Kyiv, Ukraine \\ ${ }^{2}$ Department of Surgery, Yonsei University College of Medicine, Seoul, Korea
}

Introduction. Local excision (LE) is performed for rectal neuroendocrine tumors (NETs) $<1 \mathrm{~cm}$ in size, whereas radical surgery (RS) is performed for larger tumors. The lack of data and limited number of studies support such approaches. Thus, we determined oncological outcomes after primary tumor resection in patients with rectal NETs and identified other factors of NETs that could influence oncological outcomes.

Material and methods. We retrospectively examined patients with I-III stage rectal NETs who underwent different surgical approaches, including LE or RS, in Severance Hospital, Korea between 2006 and 2017. The association between surgery extent, tumor size (TS), depth of invasion and biological factors of NETs was examined. Oncological outcomes were analyzed. Results. Local excision (LE) and radical surgery (RS) were performed in 64 and 23 patients, respectively. Patients who underwent RS were more likely to have larger TS; deeper invasion; higher grade, mitotic index, Ki-67; more lymph node metastasis (LNMts); and a higher lymphovascular invasion rate $(p<0.001)$. Most patients with TS $<1.0 \mathrm{~cm}$ underwent LE had better DFS and OS. Primary TS $>10 \mathrm{~mm}$ was an independent predictor of invasion $(p=0.001)$ whereas depth of invasion was an independent predictor of LN metastases $(p=0.003)$. In the multivariate analysis, only invasion was an independent factor associated with poor DFS and OS ( $p=0.023$ and 0.015 , respectively).

Conclusions. Local excision could be an effective method to use in treating rectal NETs in the early stage of the disease, and depth of invasion was an important factor influencing oncological outcomes. Our findings need to be confirmed in future prospective and randomized studies.

Key words: rectal neuroendocrine tumor, local excision, radical surgery, invasion, tumor size

\section{Introduction}

Rectal neuroendocrine tumors (NETs) are rare tumors accounting for approximately $2 \%$ of all rectal tumors. However, rectal NETs are the second most frequent tumors among all gastrointestinal tract NETs and account for 20\%; they have showed the highest recent increase in incidence $[1,2]$. The prognosis for rectal NETs is favorable, with a 5-year survival rate of approximately 90\% [3-5]. The current National Comprehensive Cancer Network (NCCN) and European Neuroendocrine Tumor Society (ENETS) guidelines advise providing aggressive surgical treatments for rectal NETs $>2 \mathrm{~cm}$ in size $[6,7]$. However, these size-based surgical approaches are controversial because only limited studies on these approaches are available [8-10]. Common surgical methods, including low anterior resection or APR, are used to excise rectal NETs $>2 \mathrm{~cm}$ in size $[6,11,12]$.

Endoscopic approaches, including endoscopic submucosal dissection (ESD) and endoscopic mucosal resection (EMR), enable resection of rectal NETs with small sizes $(<10 \mathrm{~mm})$ and are recommended by the ENETS 2016 guidelines [7]. However, these endoscopic methods have a high rate of positive resec-

\section{How to cite:}

Zubaryev M, Ho Seung K, Byung Soh M. Local excision vs. radical surgery in treating rectal nets considering the biology of neuroendocrine tumors (NETs). NOWOTWORY J Oncol 2021; 71: 9-16. 
tion margins (approximately 24\%-46\%) according to some modern studies $[13,14]$. Lee at al. revealed $17 \%$ positive resection margins after EMR among patients with tumors $15 \mathrm{~mm}$ in diameter [15]. Studies demonstrated a significant improvement with approximately $96 \%$ complete resections when ESR was used instead of EMR [16-18]. Transanal minimally invasive surgery (TAMIS) or transanal endoscopic microsurgery (TEM) enable safe resection of rectal NETs with negative margins, although the size is $>2 \mathrm{~cm}$ [19-20].

Some studies have suggested that the size of rectal NETs is one of the most important factors in prognosis. According to their results, positive LN metastasis significantly increase with the size of the tumor and was observed from 40 to $80 \%$ of patients with tumor size $>2 \mathrm{~cm}$ [21-25].

In contrast, a recent assessment of the SEER database showed that LN metastasis occurred in only $11.7 \%$, and distant metastases occurred in only $12 \%$ of tumors $>2 \mathrm{~cm}$ [26]. According to other modern data, there are no significant differences in oncological outcomes among patients with rectal NETs of different sizes $(<2$ or $>4 \mathrm{~cm}$ ) who underwent local excision or standard surgical approaches with disease-free LN status [26]. Moreover, there was a paradoxical contradictory report of outcomes after local excision versus radical surgery. The 10-year overall survival (OS) rates for T2 rectal NETs after local excision or radical surgery were $79.8 \%$ and $63.2 \%$ and those for T3/4 were $82.3 \%$ and $28.3 \%$, respectively $(p<0.01)$. In addition, Ki-67 $>3 \%$ and lymphatic or venous invasion were strong predictors in multivariate analysis [27].

It is worth indicating that compared with local excision approaches, low anterior resection of the rectum or abdominoperineal resection significantly compromises the quality of life (QOL) of patients. It also can be hypothesized that the biological features of NETs appear to play a more important role than the size of NETs. For example, NET features, including high Ki-67 index, high grade and mitotic index, and lymphovascular invasion are more crucial when the surgical approach is chosen and their presence results in varying prognosis $[26,28]$. However, the nature and biology of rectal NETs needs to be considered in further studies because of their increasing incidence and the promising results of local excision with no evidence of LN metastasis. The new data might prove the effectiveness of local excision with the same oncological outcomes as radical surgery but with better QOL for patients.

Thus, this study aimed to determine oncological outcomes depending on the extent of primary tumor resection in patients with I-III stage rectal NETs in addition to identifying other factors associated with NET biology and aggressiveness that can influence oncological outcomes.

\section{Materials and methods}

In this single-center, retrospective, nonrandomized study, patients with I-III stage rectal NETs who underwent different surgical treatments, including local excision or radical opera- tion, in Severance Hospital, Yonsei University Health System, Seoul, Korea between 2006 and 2017, were examined. Data were collected from the electronic medical record database of Severance Hospital. The clinicopathological characteristics, such as patients' age at diagnosis, gender, year of diagnosis, type of operation, stage, grade, differentiation, distance from AV, mitotic index, Ki-67, CD56, synaptophysin, chromogranin status, depth of invasion, and last follow-up status (alive/dead), were obtained from the database. Type of operation was defined as radical surgery, which included low anterior resection, abdominoperineal resection and intersphincter resection performed via the open or laparoscopic/robot approach; local excision was performed by TAMIS or transanal excision. All types of operations were included for retrospective analysis based on inclusion and exclusion criteria.

Based on the inclusion and exclusion criteria, patients were categorized depending on the surgical approach and clinicopathologic characteristics. The inclusion criteria were as follows: localization - rectum; stage I, II and III (AJCC TNM $7^{\text {th }}$ ed.); tumor size ranging from 1 to $50 \mathrm{~mm}$; tumor distance within $15 \mathrm{~cm}$ from the anal verge; type of operation (local excision versus radical surgery); patient's age between 19 and 80 years and the availability of histopathological and radiologic data. The exclusion criteria were as follows: stage IV (AJCC TNM $7^{\text {th }}$ ed.), patient's age $<19$ or $>80$ years, treatment for previous cancer besides rectal NETs; follow-up loss; or incomplete clinical/ histopathological/radiologic data.

The primary endpoints of this study were long-term survival outcomes of patients with rectal NETs after surgical treatment using two different approaches, namely radical surgery orTAMIS. Different factors associated with tumor biology and aggressiveness were also investigated regardless of the surgical approaches. OS was calculated from the date of surgery to the date of death. Disease-free survival (DFS) was calculated from the date of surgery to the date of recurrence.

\section{Statistical analysis}

Statistical analysis was performed using IBM SPSS StatisticS, version 23 (SPSS Inc., Chicago, IL, USA). Categorical variables were expressed as frequencies (\%), whereas continuous variables were presented as means, with their range or standard deviation. The means of continuous variables were compared using an independent sample t-test. Categorical variables were compared using the Pearson test. OS and DFS were estimated using the Kaplan-Meier method and were compared using a log-rank test. A multivariate Cox proportional hazards model with stepwise method was used to identify statistically significant independent prognostic factors for OS and DFS. In logistic regression analysis, $p$ values $<0.05$ were used to define statistical significance of variables influencing DFS. A receiver operating characteristic (ROC) curve analysis was used to determine the optimal cutoff value of the tumor size. The variance inflation factor (VIF) method was used to detect 
whether multicollinearity was presented among the independent variables (VIF > 3 indicated the existent correlation among investigated variables).

\section{Results}

Overall, 1046 patients with rectal NETs underwent different treatments. An endoscopic approach was performed in 928 patients (365, cold polypectomy and 563, EMR or ESD), local excision in 72, and radical surgery in 46. Among those, based on the study aim and eligibility criteria, we further analyzed only the clinical data of 64 patients who underwent local excision and the 23 patients who underwent radical surgery. The characteristics of both groups of patients are summarized in table I.

Table I. Patients' characteristics

\begin{tabular}{|c|c|c|c|}
\hline Variables & Radical surgery & Local excision & p \\
\hline no. of patients & 23 & 64 & \\
\hline age, mean \pm SD (years) & $52.3 \pm 11.3$ & $49.7 \pm 12.1$ & 0.420 \\
\hline $\begin{array}{l}\text { age (years) } \\
\leq 65 \\
>65\end{array}$ & $\begin{array}{c}18(78.3 \%) \\
5(21.7 \%)\end{array}$ & $\begin{array}{c}57(89.1 \%) \\
7(10.9 \%)\end{array}$ & 0.198 \\
\hline $\begin{array}{l}\text { gender } \\
\text { male } \\
\text { female }\end{array}$ & $\begin{array}{c}17(73.9 \%) \\
6(26.1 \%)\end{array}$ & $\begin{array}{l}24(37.5 \%) \\
40(62.5 \%)\end{array}$ & 0.323 \\
\hline $\begin{array}{l}\text { aprimary tumor size }(\mathbf{m m}) \\
\leq 10.2 \\
>10.2\end{array}$ & $\begin{array}{c}8(34.8 \%) \\
15(65.2 \%)\end{array}$ & $\begin{array}{l}54(84.4 \%) \\
10(15.6 \%)\end{array}$ & $<0.001$ \\
\hline $\begin{array}{l}\text { b primary tumor size }(\mathbf{m m}) \\
\leq 16.5 \\
>16.5\end{array}$ & $\begin{array}{l}12(52.2 \%) \\
11(47.8 \%)\end{array}$ & $\begin{array}{c}62(96.9 \%) \\
2(3.1 \%)\end{array}$ & $<0.001$ \\
\hline distance from $A V$, mean $\pm S D(\mathrm{~cm})$ & $7.7 \pm 3.3$ & $6.2 \pm 2.6$ & 0.038 \\
\hline $\begin{array}{l}\text { differentiation } \\
\text { well } \\
\text { moderate }\end{array}$ & $\begin{array}{c}20(87.0 \%) \\
3(13.0 \%)\end{array}$ & $\begin{array}{c}62(96.8 \%) \\
2(3.1 \%)\end{array}$ & 0.116 \\
\hline $\begin{array}{l}\text { invasion } \\
\text { mucosa }+ \text { submucosa } \\
\text { muscularis propria + pericolic tissue }\end{array}$ & $\begin{array}{c}8(34.8 \%) \\
15(65.2 \%)\end{array}$ & $\begin{array}{c}60(93.8 \%) \\
4(6.3 \%)\end{array}$ & $<0.001$ \\
\hline $\begin{array}{l}\text { grade } \\
\mathrm{G} 1 \\
\geq \mathrm{G} 2\end{array}$ & $\begin{array}{l}12(52.2 \%) \\
11(47.8 \%)\end{array}$ & $\begin{array}{c}59(92.2 \%) \\
5(7.8 \%)\end{array}$ & $<0.001$ \\
\hline $\begin{array}{l}\text { HPF } \\
\leq 2 / 10 \\
>2 / 10\end{array}$ & $\begin{array}{c}14(60.9 \%) \\
9(39.1 \%)\end{array}$ & $\begin{array}{c}61(95.3 \%) \\
3(4.7 \%)\end{array}$ & $<0.001$ \\
\hline $\begin{array}{l}\text { TNM stage } \\
I,\|A,\| B \\
\||A, I| \mid B\end{array}$ & $\begin{array}{l}13(56.5 \%) \\
10(43.5 \%)\end{array}$ & $\begin{array}{c}64(100.0 \%) \\
0\end{array}$ & $<0.001$ \\
\hline $\begin{array}{l}\text { T status } \\
\mathrm{T} 1, \mathrm{~T} 2 \\
\mathrm{~T} 3, \mathrm{~T} 4\end{array}$ & $\begin{array}{l}11(47.8 \%) \\
12(52.2 \%)\end{array}$ & $\begin{array}{c}62(96.9 \%) \\
2(3.1 \%)\end{array}$ & $<0.001$ \\
\hline $\begin{array}{l}\text { N status } \\
\text { N0 } \\
\text { N1 }\end{array}$ & $\begin{array}{l}13(56.5 \%) \\
10(43.5 \%)\end{array}$ & $\begin{array}{c}64(100.0 \%) \\
0\end{array}$ & $<0.001$ \\
\hline $\begin{array}{l}\mathbf{K i}-\mathbf{6 7} \\
\leq 2 \% \\
>2 \%\end{array}$ & $\begin{array}{c}15(65.2 \%) \\
8(34.8 \%)\end{array}$ & $\begin{array}{c}58(90.6 \%) \\
6(9.4 \%)\end{array}$ & 0.004 \\
\hline $\begin{array}{l}\text { PNIV } \\
\text { positive } \\
\text { negative }\end{array}$ & $\begin{array}{c}3(13.0 \%) \\
20(87.0 \%)\end{array}$ & $\begin{array}{c}1(1.6 \%) \\
63(98.4 \%)\end{array}$ & 0.055 \\
\hline $\begin{array}{l}\text { LVIN } \\
\text { positive } \\
\text { negative }\end{array}$ & $\begin{array}{c}9(39.1 \%) \\
14(60.9 \%)\end{array}$ & $\begin{array}{c}1(1.6 \%) \\
63(98.4 \%)\end{array}$ & $<0.001$ \\
\hline $\begin{array}{l}\text { CD56 } \\
\text { positive } \\
\text { negative }\end{array}$ & $\begin{array}{c}21(91.3 \%) \\
2(8.7 \%)\end{array}$ & $\begin{array}{l}45(70.3 \%) \\
19(29.7 \%)\end{array}$ & 0.044 \\
\hline
\end{tabular}




\begin{tabular}{|c|c|c|c|}
\hline Variables & Radical surgery & Local excision & $\mathrm{p}$ \\
\hline $\begin{array}{l}\text { synaptophysin } \\
\text { positive } \\
\text { negative }\end{array}$ & $\begin{array}{c}21(91.3 \%) \\
2(8.7 \%)\end{array}$ & $\begin{array}{l}50(78.1 \%) \\
14(21.9 \%)\end{array}$ & 0.218 \\
\hline $\begin{array}{l}\text { chromogranin } \\
\text { positive } \\
\text { negative }\end{array}$ & $\begin{array}{c}4(17.4 \%) \\
19(82.6 \%)\end{array}$ & $\begin{array}{l}16(25.0 \%) \\
48(75.0 \%)\end{array}$ & 0.457 \\
\hline
\end{tabular}

SD - standard deviation; AV - anal verge; HPF - high power field; TNM - tumor-node-metastasis; PNIV - peri-neural invasion; LVIN - lympho-vascular invasion

a cutoff based on mean value

${ }^{b}$ cutoff based on ROC curve

Patients' age, gender, differentiation of NET and some tumors markers according to immunohistochemical analysis (synaptophysin and chromogranin) were not significantly different between the two groups (all $p>0.05$ ). Patients in the radical surgery group were more likely to have larger primary tumors (65.2\% vs. 15.6\%, $p<0.001)$, deeper invasion $(65.2 \%$ vs. $7.8 \%, p<0.001)$, higher grade (39.1\% vs. $7.8 \%, p<0.001)$, higher mitotic index and Ki-67 (2/10 HPFs: 39\% vs. 4.7\%; Ki-67 >2\%: $30.4 \%$ vs. $9.4 \%, \mathrm{p}<0.001)$, T stage and LN metastasis (T3/4: 52.2\% vs. 3.1\%; N1:43.5\% vs. 0\%, $\mathrm{p}<0.001$ ) and a higher lymphovascular invasion rate $(39.1 \%$ vs. $1.6 \%, \mathrm{p}<0.001)$ than those in the local excision group. A vast majority of patients with tumors $<1.0 \mathrm{~cm}$ underwent local excision (54/64, 84.4\%), whereas those with tumors $\geq 2 \mathrm{~cm}$ underwent radical surgery (15/23, 65.2\%). Recurrence was observed in five (21.7\%) and three (4.7\%) patients in radical surgery and local excision groups, respectively $(p=0.055)$.

Typically, the tumor size is one of the most important factors that predict outcomes and subsequently the surgical approach. According to the literature, tumor size $>2 \mathrm{~cm}$ seems to be a cutoff for local excision, whereas a size between 1 and $2 \mathrm{~cm}$ remains controversial. We attempted to identify which primary tumor size would be applicable in our analysis. We used a ROC curve analysis to determine the optimal cutoff value of the tumor size that could influence oncological outcomes. The optimal cutoff value was $16.5 \mathrm{~mm}$ (sensitivity, 80\%; and specificity, 90.2\%) with an area under the curve of 0.877 (95\% confidence interval [Cl]: 0.764-0.990, $p=0.005$ ). However, only two (3.1\%) patients in the local excision group had a tumor size $>16.5 \mathrm{~mm}$ compared with 11 patients (47.8\%) in the radical surgery group $(<0.001)$, resulting in inconsistency. To identify the comparable primary tumor size for analysis in both groups, we used the descriptive method to determine the mean tumor size in all 87 patients. We found that a mean size of $10.2 \mathrm{~mm}$ was more homogenous between the two groups. Thus, 15 and 10 patients in the radical surgery and local excision groups, respectively, had a primary tumor size $>10.2 \mathrm{~mm}$. A tumor size of $10 \mathrm{~mm}$ has been previously reported as a cutoff for local excision. Considering that, the primary tumor size of $10.2 \mathrm{~mm}$ was chosen for subsequent analysis of oncological outcomes in our study.

\section{Factors associated with DFS}

DFS rates were better in the local excision group than in the radical surgery. The cumulative 1-, 3-, and 5-year DFS rates of patients were $82.6 \%, 72.9 \%$ and $68 \%$, respectively in the radical surgery group; $96.9 \%, 96.9 \%$, and $94.4 \%$, respectively in the local excision group $(\mathrm{p}<0.05)$ (table III). Factors associated with an increased risk of recurrence included the type of surgical treatment (radical surgery vs. local excision), the primary tumor size $>10 \mathrm{~mm}$, poorer differentiation of primary tumor, invasion, grade $>1$, mitotic index (>1/10 HPFs), N positivity, perineural and lymphovascular invasions and $\mathrm{Ki}-67>2 \%$ according to the univariate analysis $(p<0.05)$.

In contrast, in the multivariate analysis only deep invasion ( HR, 17.385; 95\% Cl 3.684-82.052; $<<0.001)$ was independently associated with an increased risk of tumor recurrence and influenced DFS (HR, 8.374; 95\% Cl 1.342-52.248; $p=0.023$ ). Table II provides details on the clinicopathologic factors associated with DFS.

\section{Factors associated with OS}

The cumulative 1-, 3-, and 5-year OS rates of patients were 95.7\%, $90.6 \%$ and $84.6 \%$, respectively, in the radical surgery group and $100 \%$ in all the years in the local excision group (tab. III). Factors associated with poor OS included primary tumor size $>10 \mathrm{~mm}$ and tumor invasion depth $(p<0.05)$. In the multivariate analysis, depth of invasion (mucosa/submucosa vs. muscularis propria/ pericolic tissue) was independently associated with poor OS $(H R, 15.333 ; 95 \% \mathrm{Cl}, 1.710-137.447 ; p=0.015)$ (tab. II).

DFS and OS were different between the two groups $(p=0.001)$. The 1-, 3-, and 5-year DFS and OS were longer in the local excision group than in the radical surgery group (tab. III).

\section{Influence of the depth of invasion on 1-, 3-, and 5-year OS and DFS}

Depth of invasion was an independent factor associated with higher recurrence rate and poor OS; thus, we analyzed the cumulative 1-, 3-, and 5-year DFS and OS with respect to this factor. We found that the cumulative 1-, 3-, and 5- DFS and OS rates were shorter in patients with deep invasion (muscular propria and pericolic tissue) than in those with superficial invasion (mucosa and submucosa) - regardless of the surgical approaches (tab. III; figs. 1 and 2). As shown in table III and 
Table II. Univariate and multivariate analyses for disease-free survival (DFS) and overall survival (OS) of patients with rectal NETs after local excision of the rectum or rectum resection

\begin{tabular}{|c|c|c|c|c|c|c|c|c|}
\hline \multirow[t]{3}{*}{ Variables } & \multicolumn{4}{|c|}{ Disease-free survival } & \multicolumn{4}{|c|}{ Overall survival } \\
\hline & \multicolumn{2}{|c|}{ Univariate analysis } & \multicolumn{2}{|c|}{ a Multivariate analysis } & \multicolumn{2}{|c|}{ Univariate analysis } & \multicolumn{2}{|c|}{${ }^{a}$ Multivariate analysis } \\
\hline & HR $(95 \% \mathrm{Cl})$ & $p$ & HR $(95 \% \mathrm{CI})$ & p & HR $(95 \% \mathrm{CI})$ & $p$ & HR $(95 \% \mathrm{CI})$ & $\mathbf{P}$ \\
\hline groups & $0.138(0.036-0.534)$ & 0.004 & $1.823(0.086-3.167)$ & 0.551 & $0.006(0.001-20.571)$ & 0.216 & & \\
\hline age (years) & 3.367 (0.867-13.077) & 0.08 & & & $2.557(0.266-24.612)$ & 0.416 & & \\
\hline gender & $1.168(0.302-4.519)$ & 0.822 & & & $1.449(0.240-8.754)$ & 0.686 & & \\
\hline $\begin{array}{l}\text { primary tumor } \\
\text { size (mm) }\end{array}$ & $11.790(2.496-55.686)$ & 0.002 & $3.291(0.491-22.043)$ & 0.468 & $12.453(1.387-111.771)$ & 0.024 & $4.468(0.358-55.707)$ & 0.245 \\
\hline $\begin{array}{l}\text { distance from } \\
\text { AV }(\mathrm{cm})\end{array}$ & $1.889(0.532-6.701)$ & 0.325 & & & $1.927(0.321-11.562)$ & 0.473 & & \\
\hline differentiation & $5.421(1.145-25.675)$ & 0.033 & $2.618(0.492-13.943)$ & 0.408 & $4.477(0.464-43.247)$ & 0.195 & & \\
\hline invasion & $17.385(3.684-82.052)$ & $<0.001$ & $8.374(1.342-52.248)$ & 0.023 & $15.333(1.710-137.447)$ & 0.015 & $15.333(1.710-137.447)$ & 0.015 \\
\hline grade & $5.181(1.494-17.966)$ & 0.01 & $0.156(0.003-7.929)$ & 0.89 & $2.782(0.463-16.701)$ & 0.263 & & \\
\hline HPF & $4.518(1.274-16.019)$ & 0.02 & $3.419(0.147-79.551)$ & 0.98 & $3.233(0.535-19.529)$ & 0.201 & & \\
\hline N status & $14.731(4.131-52.529)$ & $<0.001$ & $4.021(0.896-18.037)$ & 0.069 & 4973.5 (0.001-7.825E) & 0.518 & & \\
\hline Ki-67 & 4.144 (1.165-14.747) & 0.028 & $0.931(0.197-5.200)$ & 0.759 & $1.422(0.159-12.727)$ & 0.753 & & \\
\hline CD56 & $1.355(0.288-6.390)$ & 0.701 & & & $32.824(0.006-183676)$ & 0.428 & & \\
\hline synaptophysin & $0.541(0.140-2.095)$ & 0.374 & & & $28.549(0.002-381675)$ & 0.489 & & \\
\hline chromogranin & $0.376(0.048-2.966)$ & 0.353 & & & $0.033(0.001-327.922)$ & 0.468 & & \\
\hline
\end{tabular}

HR - hazard ratio; Cl - confidence interval; AV - anal verge; HPF - high power field

${ }^{a}$ Cox proportional hazards models adjusted for groups (local excision [reference], radical surgery), age ( $\leq 65$ [reference], $>65$ ), gender (male [reference], female), primary tumor size $(<10$ [reference], $\geq 10$ ), distance from AV ( $\leq 6$ [reference], $>6$ ), differentiation (well [reference], moderate), invasion (mucosa + submucosa [reference], muscularis propria + pericolic tissue), grade (G1 [reference], G2), HPF ( $\leq 2 / 10$ [reference], > 2/10), N status (N0 [reference], N1), Ki-67 ( $\leq 2 \%$ [reference], > 2\%), CD56 (negative [reference], positive), synaptophysin (negative [reference], positive), chromogranin (negative [reference], positive).

Table III. Proportion of disease-free survival and overall survival of patients with rectal neuroendocrine tumors in radical surgery and local excision groups, depending on the depth of invasion of rectal neuroendocrine tumors in both groups over 1, 3, and 5 years $(p=0.001)$

\begin{tabular}{|c|c|c|c|c|c|}
\hline \multirow[t]{2}{*}{ Time } & & \multicolumn{2}{|c|}{ Groups } & \multicolumn{2}{|c|}{ Depth of invasion } \\
\hline & & Radical surgery & Local excision & Mucosa/submucosa & Muscularis/pericolic tissue \\
\hline \multirow{2}{*}{1 year } & disease free survival & $82.6 \%$ & $96.9 \%$ & $98.5 \%$ & $78.9 \%$ \\
\hline & overall survival & $95.7 \%$ & $100 \%$ & $100 \%$ & $94.4 \%$ \\
\hline \multirow{2}{*}{3 years } & disease-free survival & $72.9 \%$ & - & $97.1 \%$ & $72.9 \%$ \\
\hline & overall survival & $90.6 \%$ & - & $100 \%$ & $87.7 \%$ \\
\hline \multirow{2}{*}{5 years } & disease-free survival & $68 \%$ & $94.4 \%$ & $97.1 \%$ & $53.1 \%$ \\
\hline & overall survival & $84.6 \%$ & $100 \%$ & $100 \%$ & $87.7 \%$ \\
\hline
\end{tabular}

figures 1 and 2, patients with rectal NETs having invasion to the mucosa and submucosa had better 1-, 3- and 5-year DFS and OS rates than those with invasion to the muscular propria and pericolic tissue in both the groups $(p=0.001)$.

\section{Factors associated with invasion and LN metastasis}

Regarding survival and recurrence rates, we identified factors associated with invasion that corresponded to poor DFS and OS.
We also investigated additional factors influencing DFS, such as LN positivity. We used logistic regression analysis to identify associated factors and compare potential factors. We included primary tumor size, grade, differentiation of primary tumor, T status, mitotic activity, synaptophysin, chromogranin, N status and invasion.

\section{Factors predicting invasion}

We analyzed factors that could predict the depth of invasion of the primary tumor. As shown in table IV, the mitotic index (HPF) 


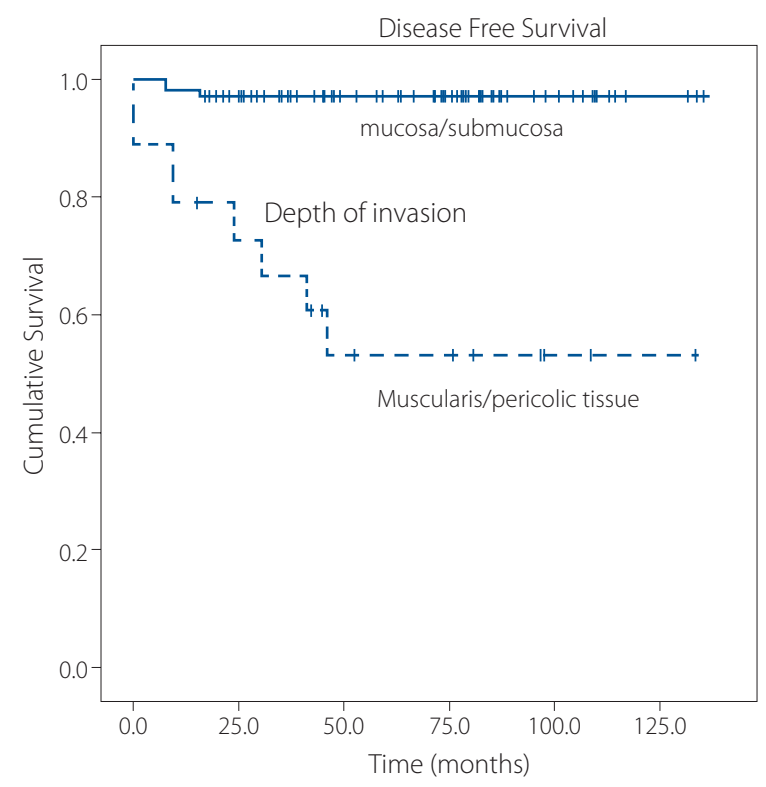

Figure 1. Disease-free survival (DFS) of patients with rectal neuroendocrine tumors (NETs) with two depths of invasion $(p<0.001)$

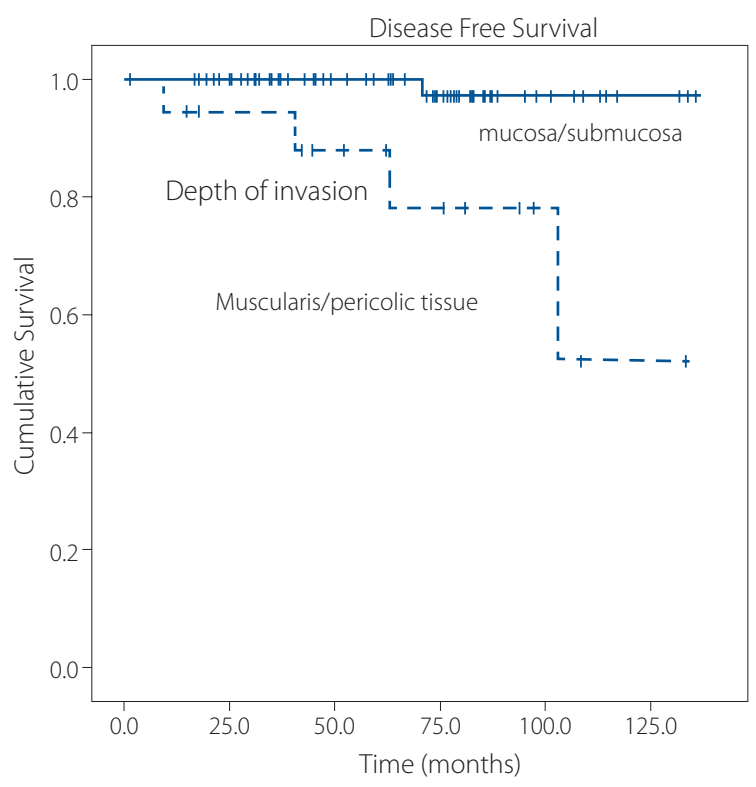

Figure 2. Overall survival (OS) of patients with rectal neuroendocrine tumors (NETs) with two depths of invasion $(p=0.001)$

Table IV. Logistic regression analysis of factors predictive for invasion

\begin{tabular}{|c|c|c|c|c|c|c|}
\hline \multirow[t]{2}{*}{ Variables } & \multicolumn{2}{|c|}{ Groups } & \multirow[b]{2}{*}{ p } & \multicolumn{3}{|c|}{ Logistic regression analysis } \\
\hline & Radical surgery & Local excision & & Odds ratio & $95 \%$ confidence interval & $p$ \\
\hline primary tumor size (>11 mm) & $15(65.2 \%)$ & $10(15.6 \%)$ & $<0.001$ & 38.515 & $4.343-341.594$ & 0.001 \\
\hline high power field ( $\geq 2 / 10$ ) & $9(39.1 \%)$ & $3(4.7 \%)$ & $<0.001$ & 55.560 & $4.711-655.309$ & 0.001 \\
\hline grade $(\geq \mathrm{G} 2)$ & $11(47.8 \%)$ & $5(7.8 \%)$ & $<0.001$ & & & $a_{-}$ \\
\hline $\mathrm{N}(+)$ & $10(43.5 \%)$ & 0 & $<0.001$ & 7.570 & $0.871-65.766$ & 0.066 \\
\hline $\mathrm{Ki}-67(>2 \%)$ & $8(34.8 \%)$ & $6(9.4 \%)$ & 0.001 & & & $a_{-}$ \\
\hline $\operatorname{CD} 56(+)$ & $21(91.3 \%)$ & $45(70.3 \%)$ & 0.802 & & & \\
\hline synaptophysin (+) & $21(91.3 \%)$ & $50(78.1 \%)$ & 0.735 & & & \\
\hline chromogranin (+) & $4(17.4 \%)$ & $16(25.0 \%)$ & 0.697 & & & \\
\hline differentiation (moderate) & $3(13.0 \%)$ & $2(3.1 \%)$ & 0.011 & & & $b_{-}$ \\
\hline
\end{tabular}

ansignificant and not presented

bExcluded by the variance inflation factor (VIF)

associated with NET biology was predictive of the depth of invasion in the univariate analysis and remained an independent predictor in the multivariate analysis (odds ratio [OR], 55.560; 95\% Cl, 4.711-655.309; $\mathrm{p}=0.001$ ). Primary tumor size $>10 \mathrm{~mm}$ was also an independent predictor of invasion according to the univariate and multivariate analyses $(\mathrm{OR}, 38.515 ; 95 \% \mathrm{Cl}$, 4.343-341.594; $p=0.001$ ).

\section{Factors predicting LN positivity}

We used the same model to investigate factors that could predict LN metastasis in the multivariate analysis. We found that only invasion of the primary tumor remained an independent predictor of LN positivity (OR $14.893 \mathrm{Cl} 2.532-87.587, \mathrm{p}=0.003$ ) in the multivariate analysis.

\section{Discussion}

According to modern data, an increasing number of patients visit hospitals with small rectal NETs because of the efficient screening program. Thus, the proportion of tumors of $\leq 10 \mathrm{~mm}$ in size with maximum invasion to the submucosa (T1) has increased over time, accounting for $45-65 \%$ of patients in recent years. This makes the local treatment of rectal NETs with good oncological outcomes feasible in many cases $[1,4,26,27]$. In our study, we failed to include a large number of cases that were treated with local excision and radical surgery because most cases had small tumors $(<10 \mathrm{~mm})$ and were treated with EMR/ESD or cold polypectomy. Nonetheless, we included a small proportion of patients with tumors $>10 \mathrm{~mm}$ in size who received bigger surgical treatments such as local excision or 
radical surgery. We analyzed the effectiveness of local excision compared with radical surgery and also challenged the main idea based on NCCN and ENETS guidelines regarding the size of primary tumors that should be considered as the most important factor when treatment is planned.

We found that the groups were quite heterogeneous for analysis. Patients in the local excision group had better DFS and OS than those in the radical surgery group. However, that was because the early stage of the disease was mostly found among patients in the group with LE. The radical surgery group included patients with larger primary tumor size, LN+, higher grade and deeper invasion. However, it is worth indicating that regardless of more aggressive NETs in patients in the radical surgery group, radical surgery could not improve the oncological outcomes.

We also investigated other factors that could influence oncological outcomes. Factors such as mitotic index, Ki-67, grade, $\mathrm{N}+$, PNIV and LVIV were insignificant and did not influenced DFS and OS according to the results of univariate and multivariate analysis. However, invasion appeared to be an independent factor influencing the DFS and OS of patients with rectal NETs. Patients with rectal NETs who had invasion beyond the submucosa layer had a poorer 1-, 3-, and 5-year DFS and OS compared with those having superficial invasion. Based on these results, we attempted to identify factors that influenced invasion. We found that tumor size $>10 \mathrm{~mm}$, mitotic index $>2$ and LN+ were independent predictors of the depth of invasion and thus influenced the recurrence rate and survival of patients. In contrast, we also revealed that the depth of invasion (beyond the submucosa) was an independent predictor of LN positivity, which predicted poor oncological outcomes in many previous studies. We suggest that the depth of invasion of primary NETs is the most important factor that should be considered when treatment strategies are planned. Our study also reviewed modern data found in much larger studies and discovered that where the size of the primary tumor or a more radical treatment failed to be independent factors of DFS and OS.

However, our study does have significant limitations such as its small sample size, selection bias owing to retrospective non-randomized data and group heterogeneity. We believe that more comparative prospective randomized studies with a larger number of cases are needed to corroborate our findings and investigate other prognostic factors of rectal NETs that can determine treatment strategies.

\section{Conclusion}

In summary, our findings demonstrated that local excision could be effective in treating rectal NETs in the early stage. They revealed that the depth of invasion was an important factor in influencing oncological outcomes. Nonetheless, our findings need to be confirmed in more prospective and randomized studies with a larger number of cases and more homogeneous data.
Conflict of interest: none declared

\author{
Mykola Zubaryev \\ National Cancer Institute \\ Department of Abdominal Tumors \\ Lomonosova 33/43 \\ Kyiv 03022, Ukraine \\ e-mail:mykola.zubaryev@gmail.com
}

Received: 17 Sep 2020

Accepted: 1 Dec 2020

\section{References}

1. Fraenkel M, Kim M, Faggiano A, et al. Knowledge NETwork. Incidence of gastroenteropancreatic neuroendocrine tumours: a systematic review of the literature. Endocr Relat Cancer. 2014; 21(3): R153-R163, doi: 10.1530/ERC-13-0125, indexed in Pubmed: 24322304.

2. Dasari A, Shen $C$, Halperin D, et al. Trends in the Incidence, Prevalence, and Survival Outcomes in Patients With Neuroendocrine Tumors in the United States. JAMA Oncol. 2017; 3(10): 1335-1342, doi: 10.1001/ jamaoncol.2017.0589, indexed in Pubmed: 28448665.

3. Maggard MA, O'Connell JB, Ko CY. Updated population-based review of carcinoid tumors. Ann Surg. 2004; 240(1): 117-122, doi: 10.1097/01. sla.0000129342.67174.67, indexed in Pubmed: 15213627.

4. Ezekian B, Adam MA, Turner MC, et al. Local excision results in comparable survival to radical resection for early-stage rectal carcinoid. J Surg Res. 2018; 230: 28-33, doi: 10.1016/j.jss.2018.04.038, indexed in Pubmed: 30100036.

5. McDermott FD, Heeney A, Courtney D, et al. Rectal carcinoids: a systematic review. Surg Endosc. 2014; 28(7): 2020-2026, doi: 10.1007/ s00464-014-3430-0, indexed in Pubmed: 24584484.

6. Shah MH, Goldner WS, Halfdanarson TR, et al. NCCN Guidelines Insights: Neuroendocrine and Adrenal Tumors, Version 2.2018. J Natl Compr Canc Netw. 2018; 16(6): 693-702, doi: 10.6004/jnccn.2018.0056, indexed in Pubmed: 29891520.

7. Delle Fave G, O'Toole D, Sundin A, et al. Vienna Consensus Conference participants. ENETS Consensus Guidelines Update for Gastroduodenal Neuroendocrine Neoplasms. Neuroendocrinology. 2016; 103(2): 119-124, doi: 10.1159/000443168, indexed in Pubmed: 26784901.

8. Wei R, Lo OSH, Law WL. Surgical management and outcome of rectal carcinoids in a university hospital. World J Surg Oncol. 2015; 13: 31, doi: 10.1186/s12957-015-0463-3, indexed in Pubmed: 25889934.

9. Yangong $\mathrm{H}$, Shi $\mathrm{C}$, Shahbaz $\mathrm{M}$, et al. Diagnosis and treatment experience of rectal carcinoid (a report of 312 cases). Int J Surg. 2014; 12(5): 408411, doi: 10.1016/j.ijsu.2014.03.002, indexed in Pubmed: 24631555.

10. Choi CW, Park SuB, Kang DH, et al. The clinical outcomes and risk factors associated with incomplete endoscopic resection of rectal carcinoid tumor. Surg Endosc. 2017; 31(12): 5006-5011, doi: 10.1007/s00464017-5497-x, indexed in Pubmed: 28936630

11. Choi AH, Kim J, Chao J. Perioperative chemotherapy for resectable gastric cancer: MAGIC and beyond. World J Gastroenterol. 2015; 21(24): 7343-7348, doi: 10.3748/wjg.v21.i24.7343, indexed in Pubmed: 26139980.

12. Takatsu Y, Fukunaga Y, Nagasaki T, et al. Short- and Long-term Outcomes of Laparoscopic Total Mesenteric Excision for Neuroendocrine Tumors of the Rectum. Dis Colon Rectum. 2017; 60(3): 284-289, doi: 10.1097/ DCR.0000000000000745, indexed in Pubmed: 28177990.

13. Park HW, Byeon JS, Park YS, et al. Endoscopic submucosal dissection for treatment of rectal carcinoid tumors. Gastrointest Endosc. 2010; 72(1): 143-149, doi: 10.1016/j.gie.2010.01.040, indexed in Pubmed: 20381798.

14. Kim JuS, Kim YJ, Chung JW, et al. Usefulness of endoscopic resection using the band ligation method for rectal neuroendocrine tumors. Intest Res. 2016; 14(2): 164-171, doi: 10.5217/ir.2016.14.2.164, indexed in Pubmed: 27175117.

15. Lee HJ, Kim SB, Shin CM, et al. A comparison of endoscopic treatments in rectal carcinoid tumors. Surg Endosc. 2016; 30(8): 3491-3498, doi: 10.1007/s00464-015-4637-4, indexed in Pubmed: 26514133.

16. Yang DH, Park Y, Park SH, et al. Cap-assisted EMR for rectal neuroendocrine tumors: comparisons with conventional EMR and endoscopic submucosal dissection (with videos). Gastrointest Endosc. 2016; 83(5): 1015-22; quiz 1023, doi: 10.1016/j.gie.2015.09.046, indexed in Pubmed: 26460225. 
17. Chen Ru, Liu X, Sun S, et al. Comparison of Endoscopic Mucosal Resection With Circumferential Incision and Endoscopic Submucosal Dissection for Rectal Carcinoid Tumor. Surg Laparosc Endosc Percutan Tech. 2016; 26(3): e56-e61, doi: 10.1097/SLE.0000000000000266, indexed in Pubmed: 27213787.

18. He L, Deng T, Luo H. Efficacy and safety of endoscopic resection therapies for rectal carcinoid tumors: a meta-analysis. Yonsei Med J. 2015; 56(1): 72-81, doi: 10.3349/ymj.2015.56.1.72, indexed in Pubmed: 25510749.

19. Kumar AS, Sidani SM, Kolli K, et al. Transanal endoscopic microsurgery for rectal carcinoids: the largest reported United States experience. Colorectal Dis. 2012; 14(5): 562-566, doi: 10.1111/j.1463-1318.2011.02726.x, indexed in Pubmed: 21831099.

20. Zhou JL, Lin GL, Zhao DC, et al. Resection of multiple rectal carcinoids with transanal endoscopic microsurgery: case report. World J Gastroenterol. 2015; 21(7): 2220-2224, doi: 10.3748/wjg.v21.i7.2220, indexed in Pubmed: 25717261.

21. Modlin IM, Lye KD, Kidd M. A 5-decade analysis of 13,715 carcinoid tumors. Cancer. 2003; 97(4): 934-959, doi: 10.1002/cncr.11105, indexed in Pubmed: 12569593.

22. Modlin IM, Oberg K, Chung DC, et al. Gastroenteropancreatic neuroendocrine tumours. Lancet Oncol. 2008; 9(1): 61-72, doi: 10.1016/ S1470-2045(07)70410-2, indexed in Pubmed: 18177818.
23. Caplin ME, Pavel M, Ćwikła JB, et al. CLARINET Investigators. Lanreotide in metastatic enteropancreatic neuroendocrine tumors. N Engl J Med. 2014; 371(3): 224-233, doi: 10.1056/NEJMoa1316158, indexed in Pubmed: 25014687.

24. Gleeson FC, Levy MJ, Dozois EJ, et al. Endoscopically identified well-differentiated rectal carcinoid tumors: impact of tumor size on the natural history and outcomes. Gastrointest Endosc. 2014; 80(1): 144-151, doi: 10.1016/j.gie.2013.11.031, indexed in Pubmed: 24462168.

25. Park $\mathrm{CH}$, Cheon JH, Kim JO, et al. Criteria for decision making after endoscopic resection of well-differentiated rectal carcinoids with regard to potential lymphatic spread. Endoscopy. 2011; 43(9): 790-795, doi: 10.1055/s-0030-1256414, indexed in Pubmed: 21735371.

26. McConnell YJ. Surgical management of rectal carcinoids: trends and outcomes from the Surveillance, Epidemiology, and End Results database (1988 to 2012). Am J Surg. 2016; 211(5): 877-885, doi: 10.1016/j. amjsurg.2016.01.008, indexed in Pubmed: 27048945.

27. Kasuga A, Chino A, Uragami N, et al. Treatment strategy for rectal carcinoids: a clinicopathological analysis of 229 cases at a single cancer institution. J Gastroenterol Hepatol. 2012; 27(12): 1801-1807, doi: 10.1111/j.1440-1746.2012.07218.x, indexed in Pubmed: 22743039.

28. Avenel P, McKendrick A, Silapaswan S, et al. Gastrointestinal carcinoids: an increasing incidence of rectal distribution. Am Surg. 2010; 76(7): 759-763, indexed in Pubmed: 20698387. 